\title{
Association between Abdominal Fat (DXA) and Its Subcomponents (CT Scan) before and after Weight Loss in Obese Postmenopausal Women: A MONET Study
}

\author{
Caroline Y. Doyon, ${ }^{1,2}$ Martin Brochu, ${ }^{1,2}$ Virginie Messier, ${ }^{3}$ Marie-Ève Lavoie,,${ }^{3,4}$ May Faraj, ${ }^{3,4}$ \\ Éric Doucet, ${ }^{5,6}$ Rémi Rabasa-Lhoret, ${ }^{3,4}$ and Isabelle J. Dionne ${ }^{1,2}$ \\ ${ }^{1}$ Research Centre on Aging, University Institute of Geriatrics of Sherbrooke, 1036 Belvedere Street South, Sherbrooke, \\ QC, Canada J1H 4C4 \\ ${ }^{2}$ Faculté d'Éducation Physique et Sportive, Université de Sherbrooke, 2500 de l'Université Boulevard, Sherbrooke, QC, Canada J1K2R1 \\ ${ }^{3}$ Unité de Recherche en Maladies Métaboliques, Institut de Recherches Cliniques de Montréal, 110 des Pins Avenue West, \\ Montreal, QC, Canada H2W $1 R 7$ \\ ${ }^{4}$ Département de Nutrition, Faculté de Médecine, Université de Montréal, Montreal, QC, Canada H3C 3J7 \\ ${ }^{5}$ School of Human Kinetics, Faculty of Health Sciences, University of Ottawa, Montpetit Hall, 125 University Avenue, \\ Ottawa, ON, Canada K1N 6N5 \\ ${ }^{6}$ Behavioral and Metabolic Research Unit, Montfort Hospital, 713 Montreal Road, Ottawa, ON, Canada K1K 0T2
}

Correspondence should be addressed to Isabelle J. Dionne, isabelle.dionne@usherbrooke.ca

Received 29 October 2010; Revised 11 January 2011; Accepted 20 January 2011

Academic Editor: Renato Pasquali

Copyright ( $) 2011$ Caroline Y. Doyon et al. This is an open access article distributed under the Creative Commons Attribution License, which permits unrestricted use, distribution, and reproduction in any medium, provided the original work is properly cited.

Introduction. Subcutaneous fat $(\mathrm{ScF})$ and visceral fat (VF) measurements using CT scan are expensive and may imply significant radiation doses. Cross-sectional studies using CT scan showed that ScF and VF are significantly correlated with abdominal fat measured by DXA (AF-DXA). The association has not been studied after a weight loss. Objective. To determine (1) the associations between AF-DXA and ScF and VF before and after weight loss and (2) the associations between their changes. Methods. 137 overweight/obese postmenopausal women were divided in two groups (1-caloric restriction or 2-caloric restriction + resistance training). AF was assessed using DXA and CT scan. Results. Correlations between AF-DXA and ScF (before: $r=0.87$, after; $r=0.87 ; P<.01$ ) and, AF-DXA and VF (before: $r=0.61$, after; $r=0.69 ; P<.01$ ) are not different before and after the weight loss. Correlations between delta AF-DXA and delta ScF $(r=0.72 ; P<.01)$ or delta VF $(r=0.51 ; P<.01)$ were found. Conclusion. The use of AF-DXA as a surrogate for VF after weight loss is questionable, but may be interesting for ScF.

\section{Introduction}

Several health risks and metabolic disorders have been associated with obesity such as lipid abnormalities, insulin resistance, type 2 diabetes, cardiovascular diseases, orthopedics complications, and certain forms of cancer [1-3]. Indeed, several studies showed that an excessive accumulation of fat in the abdominal region (AF) is strongly related to health hazards [4], including several component of the metabolic syndrome (MetS) such as insulin resistance, dyslipidemia, and elevated blood pressure as well as with proinflammatory and prothrombotic states $[1,4-11]$.
In women, the menopause-induced loss of estrogens leads to an accumulation of $\mathrm{AF}$ rather than peripheral adiposity [12-14]. The AF is composed of two main different layers, subcutaneous fat $(\mathrm{ScF})$ and visceral fat $(\mathrm{VF})$ [15]. Currently, the excessive accumulation of VF is considered as the most deleterious fat depot for the metabolic profile and health $[8,12,16-23]$, but excess of ScF is also linked to metabolism abnormalities mostly glucose metabolism disturbances [23-29] and elevated C-reactive protein levels in women [30]. Nonetheless, the implication of ScF in MetS remains unclear and has been reported to be less important than VF $[1,15,23,24,27]$. 
Studies showed that overweight and obese subjects engaged in diet- or exercise-induced weight loss programs can significantly reduce AF, ScF, and VF, which have also been correlated with improvements in the metabolic profile [31-34]. Interestingly, metabolic improvements have been reported even with weight losses as small as 5\% to $10 \%$ [31-35]. Studies also reported that individuals participating in a structured exercise program can lose significant $\mathrm{AF}$ amount (particularly VF), even in the absence of body weight loss [32-34, 36]. Because of the metabolic and health risks associated with VF, it is important to promote weight loss strategies that specifically target decreases in VF.

The accurate measurement of $\mathrm{AF}, \mathrm{ScF}$ and VF can be done using computed tomography (CT scan) or magnetic resonance imaging (MRI). In fact, the measurement of VF with these methods is expensive and limited due to the accessibility to the equipment. The use of CT scan has also raised some concerns regarding the exposition of subjects to radiation doses [37-39]. Hence, developing highly reliable surrogate measures of $\mathrm{VF}$ and $\mathrm{ScF}$ using simpler, less expensive and more widely available techniques would be highly useful [40]. Considering these criteria, AF measured by DXA (AF-DXA) may be an interesting alternative. A few cross-sectional studies reported that AF by DXA is significantly and strongly correlated with AF measured by CT scans (AF-CT) ( $r$ ranging from 0.86 to $0.98 ; P \leq .001$ ) $[38,41,42]$. It remains to be determined, however, if changes in AF-DXA can correctly predict changes in ScF and VF after a weight loss intervention.

The main objectives of this study were (1) to determine the association between AF measured by DXA and ScF, $\mathrm{VF}$ and AF measured by CT scan after weight loss in obese postmenopausal women, (2) to examine associations between changes in these variables after weight loss. Finally a second-level objective is to evaluate if AF-DXA could be a good surrogate of single-slice CT scan assessment of ScF and VF after a weight loss and to detect changes induced by weight loss in these compartments.

\section{Materials/Subjects and Methods}

2.1. Subjects. The MONET project (Montreal Ottawa New Emerging Team in Obesity) is designed to investigate, using a randomized controlled design, the impact of resistance training during weight loss (6 months) on various parameters including body composition as previously reported [ 43 , 44]. Briefly 137 overweight/obese postmenopausal women were randomly assigned in a $2: 1$ fashion to a 6-month caloric restriction diet (CR) alone or a CR diet + resistance training program (RT). During the 6-month weight loss phase, 30 women out of 137 dropped out of the study, yielding a dropout rate of $21.9 \%$. Thus, 107 women (71 $\mathrm{CR}$ and $36 \mathrm{RT}+\mathrm{CR}$ ) completed the 6-month weight loss phase [45]. Baseline characteristics of dropouts were not different from those of subjects who completed the study, except for lean body mass which was lower in dropouts $(40.6 \pm 3.8$ versus $42.8 \pm 6.6, P<.05)$ (results not showed). This study was approved by the Université de
Montréal Ethics Committee. After receiving a complete verbal and written description of the experimental protocol and potential risks, each participant provided signed consent.

Women were eligible to participate if they were sedentary, overweight, or obese and did not present significant health complications. Complete inclusion and exclusion criteria have previously been reported [43]. For the purpose of this study, we first selected a sample composed of 131 obese post-menopausal women $(57.6 \pm 4.8 \mathrm{yrs})$ for whom we had all baseline anthropometric, DXA, and CT scan data. We use this sample to perform correlations at baseline between AF by DXA and ScF and VF by CT scan. Secondly, to assess differences between groups at baseline and to examine changes following the intervention within each group, we selected from the previous mentioned sample all women who completed the weight loss program and in whom we had all 6-month anthropometric, DXA, and CT scan data (total $n=92$ ). These women were distributed as follows: CR group $(n=64)$ and $\mathrm{CR}+\mathrm{RT}(n=28)$.

\subsection{Caloric Restriction Intervention with or without Resistance Training Intervention. All study participants entered a 6- month weight loss program aimed at reducing body weight by $10 \%$ using a standardized diet with $55 \%, 30 \%$, and $15 \%$ of energy intake from carbohydrates, total fat, and protein according to the American Heart Association [46]. \\ A subset also participated to a 6-month resistance training program. Details about these interventions have been previously reported [43].}

2.3. Anthropometry. Body weight was measured to the nearest $0.1 \mathrm{~kg}$ on a calibrated scale (Balance Industrielle Montréal, Montréal, Québec, Canada) and subject's height was obtained with a standard stadiometer (Perspective Enterprises, Portage, MI, USA). Percentage of fat (\%F) and total fat were measured using dual energy X-ray absorptiometry (DXA) (General Electric Lunar Prodigy, Madison, WI, USA; software version 6.10.019), as previously described [31, 47]. The amount of abdominal fat (AF-DXA) is automatically generated in the DXA body composition report obtained by a whole-body assessment, as well as other regions (arms and legs). During the procedure, subjects were asked to wear only a standard hospital gown while in the supine position. Calibration was performed daily with a standard phantom. In our laboratory, the intraclass coefficient correlation for test-retest for AT and lean body mass was 0.99 $(n=18)$.

2.4. Computed Tomography. A CT scanner (GE LightSpeed 16, General Electric Medical Systems, Milwaukee, WY, USA) was used to measure the visceral fat (VF) and the abdominal subcutaneous tissue $(\mathrm{ScF})$ area. The sum of $\mathrm{ScF}$ and VF was used to calculate the abdominal fat by CT (AF-CT). Subjects were examined in the supine position with both arms stretched above their head. The position of the scan was established at the L4-L5 vertebral disc using a scout image of the body [31, 47]. We quantified VF by delineating 
TABLE 1: Descriptive characteristics.

\begin{tabular}{lccr}
\hline & Baseline $n=131$ & 6 months $n=92$ & Changes $n=92$ \\
\hline Age (years) & $57.6 \pm 4.8$ & & $78.8 \pm 12.8^{*}$ \\
Weight $(\mathrm{kg})$ & $83.2 \pm 12.6$ & $30.4 \pm 4.2^{*}$ & $-5.2 \pm 5.0$ \\
BMI $\left(\mathrm{kg} / \mathrm{m}^{2}\right)$ & $32.4 \pm 4.3$ & $91.0 \pm 9.3^{*}$ & $-2.0 \pm 1.9$ \\
WC $(\mathrm{cm})$ & $95.8 \pm 9.2$ & $15.6 \pm 4.7^{*}$ & $-5.0 \pm 4.0$ \\
AF-DXA & $18.2 \pm 5.0$ & $578.0 \pm 148.6^{*}$ & $-2.6 \pm 2.5$ \\
AF-CT & $650.8 \pm 143.9$ & $417.1 \pm 114.8^{*}$ & $-71.3 \pm 65.6$ \\
ScF & $466.0 \pm 112.9$ & $160.9 \pm 57.1^{*}$ & $-49.7 \pm 45.1$ \\
VF & $184.8 \pm 55.2$ & $-21.6 \pm 29.9$ \\
\hline
\end{tabular}

Mean \pm SD.

*Significant difference within group between 0-month and 6-month measures, $P \leq .05$.

BMI: Body Mass Index $\left(\mathrm{kg} / \mathrm{m}^{2}\right)$; WC: Waist Circumference $(\mathrm{cm})$; AF-DXA: Abdominal Fat by DXA $(\mathrm{kg})$; AF-CT: Abdominal Fat by CT scan $\left(\mathrm{cm}^{2}\right)$; ScF : Abdominal Subcutaneous Fat by CT scan $\left(\mathrm{cm}^{2}\right)$; VF : Visceral Fat by CT scan $\left(\mathrm{cm}^{2}\right)$.

the intraabdominal cavity at the internal most aspect of the abdominal and oblique muscle walls surrounding the cavity and the posterior aspect of the vertebral body. The abdominal ScF area was quantified by highlighting fat located between the skin and the external most aspect of the abdominal muscle wall. The cross-sectional areas of fat were highlighted and computed using an attenuation range of -190 to -30 Hounsfield Units (HU).

2.5. Statistical Analyses. Results are presented as the mean \pm standard deviation $( \pm S D)$. First, unpaired $t$-tests were performed to compare groups, while ANOVA for repeated measures were used to examine changes following the intervention within each group and between groups (time $x$ group interaction). Since no difference was observed between groups for $\mathrm{AF}, \mathrm{ScF}$, and $\mathrm{VF}$ before and after interventions (results not shown), data were pooled for statistical analyses purposes. Finally, Pearson correlations were used to assess the association between AF-DXA (by DXA) and ScF, VF, and AF-CT (by CT scan). To perform Pearson correlation coefficients we considered all the women for whom we had complete data for AF-DXA, ScF, VF and AF-CT. These statistical analyses were performed using Statistical Package for the Social Sciences (SPSS) version 15.0 (SPSS Inc., Chicago, IL, USA). Finally, we computed $Z$ scores from our correlation coefficients to compare the slopes from pre- and postintervention correlations. The level of significance was set at $P \leq .05$.

\section{Results}

Descriptive characteristics are presented in Table 1. As previously reported, significant differences were found between baseline and postinterventions values [43]. Correlations between AF-DXA, AF-CT, ScF, VF and WC before and after weight loss were all statistically significant (Tables 2 and 3 ; all $P$-values $<.01)$ and equivalent before and after the intervention. Pearson's correlations were also performed to assess association between changes in AF-DXA, AF-CT, ScF, VF, and WC (Table 4). Significant correlations were also
TABLE 2: Pearson's correlations between AF-DXA, AF-CT, ScF, VF, and WC before weight loss interventions.

\begin{tabular}{lccccc}
\hline & AF-DXA & AF-CT & ScF & VF & WC \\
\hline AF-DXA & 1 & & & & \\
AF-CT & $0.92^{*}$ & 1 & & & \\
ScF & $0.87^{*}$ & $0.94^{*}$ & 1 & & \\
VF & $0.61^{*}$ & $0.69^{*}$ & $0.39^{*}$ & 1 & \\
WC & $0.86^{*}$ & $0.84^{*}$ & $0.73^{*}$ & $0.70^{*}$ & 1 \\
\hline
\end{tabular}

${ }^{*} P \leq .01$ by Pearson's correlation coefficient.

AF-DXA: Abdominal Fat by DXA (kg); AF-CT: Abdominal Fat by CT (SAT+VAT) $\left(\mathrm{cm}^{2}\right)$; ScF : Abdominal Subcutaneous Fat by CT scan $\left(\mathrm{cm}^{2}\right)$; VF: Visceral Fat by CT scan $\left(\mathrm{cm}^{2}\right)$; WC: Waist Circumference $(\mathrm{cm})$.

TABle 3: Pearson's correlations between AF-DXA, AF-CT, ScF, VF, and WC after weight loss interventions.

\begin{tabular}{lccccc}
\hline & AF-DXA & AF-CT & ScF & VF & WC \\
\hline AF-DXA & 1 & & & & \\
AF-CT & $0.92^{*}$ & 1 & & & \\
ScF & $0.86^{*}$ & $0.94^{*}$ & 1 & & \\
VF & $0.67^{*}$ & $0.72^{*}$ & $0.43^{*}$ & 1 & \\
WC & $0.89^{*}$ & $0.87^{*}$ & $0.79^{*}$ & $0.69^{*}$ & 1 \\
\hline
\end{tabular}

${ }^{*} P \leq .01$ by Pearson's correlation coefficient.

AF-DXA: Abdominal Fat by DXA (kg); AF-CT: Abdominal Fat by CT (SAT+VAT) $\left(\mathrm{cm}^{2}\right)$; ScF: Abdominal Subcutaneous Fat by CT scan $\left(\mathrm{cm}^{2}\right)$; VF: Visceral Fat by CT scan $\left(\mathrm{cm}^{2}\right)$; WC: Waist Circumference $(\mathrm{cm})$.

obtained between (1) delta AF-DXA and delta ScF $(r=$ $0.720 ; P<.01),(2)$ delta AF-DXA and delta VF $(r=0.506$; $P<.01)$, and $(3)$ delta AF-DXA and delta AF-CT $(r=0.722$; $P<.01)$.

\section{Discussion}

The direct measurements of ScF and VF using multiple slices by CT scan or using MRI are currently considered as gold standard methods [29, 48]. However, these techniques are expensive and not easily accessible. Furthermore, because 
TABLE 4: Pearson's correlations between changes in AF-DXA, AF$\mathrm{CT}, \mathrm{ScF}, \mathrm{VF}$, and WC.

\begin{tabular}{llllll}
\hline & $\begin{array}{l}\text { Delta } \\
\text { AF-DXA }\end{array}$ & $\begin{array}{l}\text { Delta } \\
\text { AF-CT }\end{array}$ & Delta ScF & Delta VF & $\begin{array}{l}\text { Delta } \\
\text { WC }\end{array}$ \\
\hline $\begin{array}{llllll}\text { Delta } \\
\text { AF-DXA }\end{array}$ & 1 & & & & \\
Delta AF-CT & $0.74^{*}$ & 1 & & & \\
Delta ScF & $0.74^{*}$ & $0.92^{*}$ & 1 & & \\
Delta VF & $0.51^{*}$ & $0.81^{*}$ & $0.51^{*}$ & 1 & \\
Delta WC & $0.58^{*}$ & $0.57^{*}$ & $0.52^{*}$ & $0.47^{*}$ & 1 \\
\hline
\end{tabular}

${ }^{*} P \leq .01$ by Pearson's correlation coefficient.

AF-DXA: Abdominal Fat by DXA (kg); AF-CT: Abdominal Fat by CT (SAT+VAT) $\left(\mathrm{cm}^{2}\right)$; ScF: Abdominal Subcutaneous Fat by CT scan $\left(\mathrm{cm}^{2}\right)$; VF: Visceral Fat by CT scan $\left(\mathrm{cm}^{2}\right)$; delta AF-DXA: $($ AF-DXA 6 month - AFDXA $_{\text {baseline }}$ ); delta AF-CT: (AAT-CT mmonth $-\mathrm{AAT}_{\mathrm{CT}} \mathrm{CT}_{\text {baseline }}$ ); delta ScF: $\left(\mathrm{SAT}_{6 \text { month }}-\mathrm{SAT}_{\text {baseline }}\right)$; delta VF: $\left(\mathrm{VAT}_{6 \text { month }}-\mathrm{VAT}_{\text {baseline }}\right)$; delta WC: ( $\left.\mathrm{WC}_{6 \text { month }}-\mathrm{WC}_{\text {baseline }}\right)$.

CT scans expose subjects to radiation doses (ranging from $1.5 \mathrm{mSv}$ to $10 \mathrm{mSv}$; with an average of $6 \mathrm{mSv}$ for a spine assessment), they might not be recommended for repeated measurements $[38,39]$. For the purpose of the present study, only a single slice at L4-L5 was acquired, which corresponded to a dose of $0.012 \mathrm{mSv}$. Considering the lower cost of use, the shorter time of data acquisition and the lower ionizing radiation doses of DXA (about $0.0013 \mathrm{mSv}$ for a whole-body assessment) [37-39], it could be an interesting alternative to assess changes in VF and ScF after weight loss interventions.

The present study showed that correlations obtained between AF by DXA and AF-CT subcomponents before and after weight loss ranged from moderate to good [15] and were all significant and are similar before and after weight loss. Our results are in agreement with those of Snijder et al. (2002) obtained in a study conducted in black and white men and women aged between 70 and 79 years [49]. However, results from other studies do not agree with ours $[50,51]$. The latter studies showed abdominal fat measures by DXA to be strongly correlated with VF measured by CT scan or MRI ( $r$ between 0.83 and 0.90 ). Discrepancies between our results and others are most likely due to differences in populations studied. Indeed, in the present study, our population was composed of obese postmenopausal women as opposed to studies done in leaner men and women [50] or men only [51]. Hence, our results suggest that it is more difficult to predict changes in VF and ScF using DXA in obese postmenopausal women. This explains the lowest correlation between changes in AF-DXA and changes in VF in the present study.

Parallel to our observations pre- and post intervention, Clasey et al. also reported that DXA-derived AF is not a better predictor of VF by CT scan than WC [50]. In our study, AF-DXA accounted for only $45 \%$ of the variance of VF after weight loss, and only $26 \%$ of the variance of changes in this compartment as compared to $79 \%$ post intervention and $34 \%$ of changes for WC. Then, in our opinion, these relationships are too low to justify the use of a simple measure of abdominal fat using DXA to assess changes in the amount of visceral fat after weight loss. Thus, it seems clinically more relevant to pursue using WC to estimate the amount of VF after weight loss.

Interestingly, we also observed better correlations for ScF with AF-DXA than for VF with AF-DXA, both before and after weight loss. Indeed, the simple measure of AF-DXA accounted for $74 \%$ of the variance of $\mathrm{ScF}$ after weight loss, and for $76 \%$ of the variance of its changes. These results suggest that DXA may be an interesting surrogate to CT scan to estimate amount of ScF after weight loss and its changes, depending on the precision required.

Nonetheless, other authors have developed equations using anthropometric and/or DXA measures to estimate VF accumulations in order to downplay the limitations associated with the use of indirect measures of body fat distribution [16, 38, 41, 42, 49-55]. For example, Garaulet et al. (2006) developed a predictive equation of VF using 3 anthropometric variables (triceps skinfold, sagittal diameter and coronal diameter). The authors reported a significant but moderate correlation with VF measured by CT scan $(r=0.68 ; P<.0001)$ [52]. In another study conducted in 71 overweight and obese subjects $(27$ men and 44 women, aged between 16 and 70 years), Bertin et al. (2000) developed an equation strongly correlated with VF measured by CT scan $(r=0.86 ; P<.0001)[16]$. Their equations must however be used with caution since, to our knowledge, they had never been validated in another population including weight-reduced obese individuals.

In conclusions, cross-sectional analyses revealed good to very good correlations between AF-DXA and ScF or AF-CT before and after weight loss. On the other hand, changes in AF-DXA were only moderately correlated to changes in VF. In the light of our results, the use of CT scan remains the best approach to precisely quantify the effect of weight loss on VF. However, DXA may be an interesting surrogate to estimate the amount and changes in total abdominal fat or ScF before and after a weight loss intervention in obese postmenopausal women.

\section{Acknowledgments}

This study was supported by grants from the Canadian Institute of Health Research (CIHR)-New and Emerging Teams in Obesity (Université de Montréal and University of Ottawa; MONET project); C. Y. Doyon obtained a grant by $C I H R$; É. Doucet and M. Faraj are recipients of a CIHR/Merck-Frosst New Investigator Award; M.-È. Lavoie, R. R.-Lhoret and I. J. Dionne were supported by the Fonds de la Recherche en Santé du Québec (FRSQ); É. Doucet is a recipient of an Early Researcher Award (Ministry of Research and Innovation, Ontario CANADA); É. Doucet, M. Brochu, and I. J. Dionne obtained funds from Canadian Foundation for Innovation New Opportunities Award for equipment. The MONET group thanks patients for their exceptional involvement in this study.

\section{Conflict of Interests}

The authors have no conflict of interests to disclose. 


\section{References}

[1] J. P. Després, "Cardiovascular disease under the influence of excess visceral fat," Critical Pathways in Cardiology, vol. 6, no. 2, pp. 51-59, 2007.

[2] X. Formiguera and A. Cantón, "Obesity: epidemiology and clinical aspects," Best Practice and Research in Clinical Gastroenterology, vol. 18, no. 6, pp. 1125-1146, 2004.

[3] D. P. Guh, W. Zhang, N. Bansback, Z. Amarsi, C. L. Birmingham, and A. H. Anis, "The incidence of co-morbidities related to obesity and overweight: a systematic review and meta-analysis," BMC Public Health, vol. 9, Article ID 88, 2009.

[4] J. Vague, "La diffférenciacion sexuelle, facteur déterminant des formes de l'obésité," La Presse Médicale, vol. 55, no. 30, p. 339, 1947.

[5] G. Alfonzo-González, E. Doucet, N. Alméras, C. Bouchard, and A. Tremblay, "Estimation of daily energy needs with the FAO/WHO/UNU 1985 procedures in adults: comparison to whole-body indirect colorimetry measurements," European Journal of Clinical Nutrition, vol. 58, no. 8, pp. 1125-1131, 2004.

[6] J. P. Després, I. Lemieux, J. Bergeron et al., "Abdominal obesity and the metabolic syndrome: contribution to global cardiometabolic risk," Arteriosclerosis, Thrombosis, and Vascular Biology, vol. 28, no. 6, pp. 1039-1049, 2008.

[7] J. P. Després, I. Lemieux, A. Tchernof, C. Couillard, A. Pascot, and S. Lemieux, "Fat distribution and metabolism," Diabetes and Metabolism, vol. 27, no. 2, part 2, pp. 209-214, 2001.

[8] A. Gastaldelli, Y. Miyazaki, M. Pettiti et al., "Metabolic effects of visceral fat accumulation in type 2 diabetes," Journal of Clinical Endocrinology and Metabolism, vol. 87, no. 11, pp. 5098-5103, 2002.

[9] I. Lemieux, A. Pascot, D. Prud'homme et al., "Elevated Creactive protein: another component of the atherothrombotic profile of abdominal obesity," Arteriosclerosis, Thrombosis, and Vascular Biology, vol. 21, no. 6, pp. 961-967, 2001.

[10] K. M. Rexrode, V. J. Carey, C. H. Hennekens et al., "Abdominal adiposity and coronary heart disease in women," Journal of the American Medical Association, vol. 280, no. 21, pp. 1843-1848, 1998.

[11] A. M. Sharma, "Adipose tissue: a mediator of cardiovascular risk," International Journal of Obesity, vol. 26, supplement 4, pp. S5-S7, 2002.

[12] M. Garaulet, F. Pérez-Llamas, J. C. Baraza et al., "Body fat distribution in pre- and post-menopausal women: metabolic and anthropometric variables," Journal of Nutrition, Health and Aging, vol. 6, no. 2, pp. 123-126, 2002.

[13] M. J. Toth, A. Tchernof, C. K. Sites, and E. T. Poehlman, "Menopause-related changes in body fat distribution," Annals of the New York Academy of Sciences, vol. 904, pp. 502-506, 2000.

[14] M. J. Toth, A. Tchernof, C. K. Sites, and E. T. Poehlman, "Effect of menopausal status on body composition and abdominal fat distribution," International Journal of Obesity, vol. 24, no. 2, pp. 226-231, 2000.

[15] C. S. Fox, J. M. Massaro, U. Hoffmann et al., "Abdominal visceral and subcutaneous adipose tissue compartments: association with metabolic risk factors in the framingham heart study," Circulation, vol. 116, no. 1, pp. 39-48, 2007.

[16] E. Bertin, C. Marcus, J. C. Ruiz, J. P. Eschard, and M. Leutenegger, "Measurement of visceral adipose tissue by DXA combined with anthropometry in obese humans," International Journal of Obesity, vol. 24, no. 3, pp. 263-270, 2000.
[17] M. Brochu, R. D. Starling, A. Tchernof, D. E. Matthews, E. Garcia-Rubi, and E. T. Poehlman, "Visceral adipose tissue is an independent correlate of glucose disposal in older obese postmenopausal women," Journal of Clinical Endocrinology and Metabolism, vol. 85, no. 7, pp. 2378-2384, 2000.

[18] M. Côté, P. Mauriège, J. Bergeron et al., "Adiponectinemia in visceral obesity: impact on glucose tolerance and plasma lipoprotein and lipid levels in men," Journal of Clinical Endocrinology and Metabolism, vol. 90, no. 3, pp. 1434-1439, 2005.

[19] J. L. Lillo, “The endocannabinoid system as a novel approach for managing obesity," The Journal of the American Osteopathic Association, vol. 107, no. 4, supplement 2, pp. S12-S20, 2007.

[20] P. Mathieu, P. Pibarot, É. Larose, P. Poirier, A. Marette, and J. P. Després, "Visceral obesity and the heart," International Journal of Biochemistry and Cell Biology, vol. 40, no. 5, pp. 821-836, 2008.

[21] H. S. Park, J. Y. Park, and R. Yu, "Relationship of obesity and visceral adiposity with serum concentrations of CRP, TNF- $\alpha$ and IL-6," Diabetes Research and Clinical Practice, vol. 69, no. 1, pp. 29-35, 2005.

[22] A. Pascot, J. P. Després, I. Lemieux et al., "Deterioration of the metabolic risk profile in women. Respective contributions of impaired glucose tolerance and visceral fat accumulation," Diabetes Care, vol. 24, no. 5, pp. 902-908, 2001.

[23] B. L. Wajchenberg, D. Giannella-Neto, M. E. R. Da Silva, and R. F. Santos, "Depot-specific hormonal characteristics of subcutaneous and visceral adipose tissue and their relation to the metabolic syndrome," Hormone and Metabolic Research, vol. 34, no. 11-12, pp. 616-621, 2002.

[24] N. Abate, "Insulin resistance and obesity: the role of fat distribution pattern," Diabetes Care, vol. 19, no. 3, pp. 292294, 1996.

[25] B. H. Goodpaster, F. L. Thaete, J. A. Simoneau, and D. E. Kelley, "Subcutaneous abdominal fat and thigh muscle composition predict insulin sensitivity independently of visceral fat," Diabetes, vol. 46, no. 10, pp. 1579-1585, 1997.

[26] P. Mauriège, M. Brochu, D. Prud'homme et al., "Is visceral adiposity a significant correlate of subcutaneous adipose cell lipolysis in men?" Journal of Clinical Endocrinology and Metabolism, vol. 84, no. 2, pp. 736-742, 1999.

[27] A. Misra, "Relationship of anterior and posterior subcutaneous abdominal fat to insulin sensitivity in nondiabetic men," Obesity Research, vol. 5, no. 2, pp. 93-99, 1997.

[28] S. A. Porter, J. M. Massaro, U. Hoffmann, R. S. Vasan, C. J. O’Donnel, and C. S. Fox, "Abdominal subcutaneous adipose tissue: a protective fat depot?" Diabetes Care, vol. 32, no. 6, pp. 1068-1075, 2009.

[29] F. L. Thaete, S. R. Colberg, T. Burke, and D. E. Kelley, "Reproducibility of computed tomography measurement of visceral adipose tissue area," International Journal of Obesity, vol. 19, no. 7, pp. 464-467, 1995.

[30] A. Cartier, M. Côté, I. Lemieux et al., "Sex differences in inflammatory markers: what is the contribution of visceral adiposity?" American Journal of Clinical Nutrition, vol. 89, no. 5, pp. 1307-1314, 2009.

[31] M. Brochu, A. Tchernof, A. N. Turner, P. A. Ades, and E. T. Poehlman, "Is there a threshold of visceral fat loss that improves the metabolic profile in obese postmenopausal women?" Metabolism, vol. 52, no. 5, pp. 599-604, 2003.

[32] S. Lee, J. L. Kuk, L. E. Davidson et al., "Exercise without weight loss is an effective strategy for obesity reduction in obese individuals with and without type 2 diabetes," Journal of Applied Physiology, vol. 99, no. 3, pp. 1220-1225, 2005. 
[33] R. Ross, D. Dagnone, P. J. H. Jones et al., "Reduction in obesity and related comorbid conditions after diet-induced weight loss or exercise-induced weight loss in men: a randomized, controlled trial," Annals of Internal Medicine, vol. 133, no. 2, pp. 92-103, 2000.

[34] R. Ross, I. Janssen, J. Dawson et al., "Exercise-induced reduction in obesity and insulin resistance in women: a randomized controlled trial," Obesity Research, vol. 12, no. 5, pp. 789-798, 2004.

[35] T. B. Chaston and J. B. Dixon, "Factors associated with percent change in visceral versus subcutaneous abdominal fat during weight loss: findings from a systematic review," International Journal of Obesity, vol. 32, no. 4, pp. 619-628, 2008.

[36] T. Okura, Y. Nakata, D. J. Lee, K. Ohkawara, and K. Tanaka, "Effects of aerobic exercise and obesity phenotype on abdominal fat reduction in response to weight loss," International Journal of Obesity, vol. 29, no. 10, pp. 1259-1266, 2005.

[37] J. Haarbo, A. Gotfredsen, C. Hassager, and C. Christiansen, "Validation of body composition by dual energy X-ray absorptiometry (DEXA)," Clinical Physiology, vol. 11, no. 4, pp. 331-341, 1991.

[38] M. D. Jensen, J. A. Kanaley, J. E. Reed, and P. F. Sheedy, "Measurement of abdominal and visceral fat with computed tomography and dual-energy X-ray absorptiometry," American Journal of Clinical Nutrition, vol. 61, no. 2, pp. 274-278, 1995.

[39] F. A. Mettler, W. Huda, T. T. Yoshizumi, and M. Mahesh, "Effective doses in radiology and diagnostic nuclear medicine: a catalog," Radiology, vol. 248, no. 1, pp. 254-263, 2008.

[40] C. F. Njeh, T. Fuerst, D. Hans, G. M. Blake, and H. K. Genant, "Radiation exposure in bone mineral density assessment," Applied Radiation and Isotopes, vol. 50, no. 1, pp. 215-236, 1999.

[41] S. G. Glickman, C. S. Marn, M. A. Supiano, and D. R. Dengel, "Validity and reliability of dual-energy X-ray absorptiometry for the assessment of abdominal adiposity," Journal of Applied Physiology, vol. 97, no. 2, pp. 509-514, 2004.

[42] O. L. Svendsen, C. Hassager, I. Bergmann, and C. Christiansen, "Measurement of abdominal and intra-abdominal fat in postmenopausal women by dual energy X-ray absorptiometry and anthropometry: comparison with computerized tomography," International Journal of Obesity, vol. 17, no. 1, pp. 45-51, 1993.

[43] M. Brochu, M. F. Malita, V. Messier et al., "Resistance training does not contribute to improving the metabolic profile after a 6-month weight loss program in overweight and obese postmenopausal women," Journal of Clinical Endocrinology and Metabolism, vol. 94, no. 9, pp. 3226-3233, 2009.

[44] V. Messier, R. Rabasa-Lhoret, E. Doucet et al., "Effects of the addition of a resistance training programme to a caloric restriction weight loss intervention on psychosocial factors in overweight and obese post-menopausal women: a montreal ottawa new emerging team study," Journal of Sports Sciences, vol. 28, no. 1, pp. 83-92, 2010.

[45] V. Messier, J. Hayek, A. D. Karelis et al., "Anthropometric, metabolic, psychosocial and dietary factors associated with dropout in overweight and obese postmenopausal women engaged in a 6-month weight loss programme: a MONET study," British Journal of Nutrition, vol. 103, no. 8, pp. 12301235, 2010.

[46] R. M. Krauss, R. J. Deckelbaum, N. Ernst et al., "Dietary guidelines for healthy American adults: a statement for health professionals from the Nutrition Committee, American Heart Association," Circulation, vol. 94, no. 7, pp. 1795-1800, 1996.
[47] M. Brochu, M. E. Mathieu, A. D. Karelis et al., "Contribution of the lean body mass to insulin resistance in postmenopausal women with visceral obesity: a monet study," Obesity, vol. 16, no. 5, pp. 1085-1093, 2008.

[48] J. Kullberg, C. Von Below, L. Lönn, L. Lind, H. Ahlström, and L. Johansson, "Practical approach for estimation of subcutaneous and visceral adipose tissue," Clinical Physiology and Functional Imaging, vol. 27, no. 3, pp. 148-153, 2007.

[49] M. B. Snijder, M. Visser, J. M. Dekker et al., "The prediction of visceral fat by dual-energy X-ray absorptiometry in the elderly: a comparison with computed tomography and anthropometry," International Journal of Obesity, vol. 26, no. 7, pp. 984-993, 2002.

[50] J. L. Clasey, C. Bouchard, C. D. Teates et al., "The use of anthropometric and dual-energy X-ray absorptiometry (DXA) measures to estimate total abdominal and abdominal visceral fat in men and women," Obesity Research, vol. 7, no. 3, pp. 256-264, 1999.

[51] Y.-W. Park, S. B. Heymsfield, and D. Gallagher, "Are dualenergy X-ray absorptiometry regional estimates associated with visceral adipose tissue mass?" International Journal of Obesity, vol. 26, no. 7, pp. 978-983, 2002.

[52] M. Garaulet, J. J. Hernández-Morante, F. J. Tébar, S. Zamora, and M. Canteras, "Two-dimensional predictive equation to classify visceral obesity in clinical practice," Obesity, vol. 14, no. 7, pp. 1181-1191, 2006.

[53] E. G. Kamel, G. McNeill, and M. C. W. Van Wijk, "Usefulness of anthropometry and DXA in predicting intra-abdominal fat in obese men and women," Obesity Research, vol. 8, no. 1, pp. 36-42, 2000.

[54] Y. S. Suh, D. H. Kim, and I. K. Lee, "Usefulness of lumbar AP spine DXA for measuring the percentage of perilumbar regional fat and predicting visceral fat in obese postmenopausal women," Nutrition, vol. 18, no. 1, pp. 84-85, 2002.

[55] M. S. Treuth, G. R. Hunter, T. Kekes-Szabo, R. L. Weinsier, M. I. Goran, and L. Berland, "Reduction in intra-abdominal adipose tissue after strength training in older women," Journal of Applied Physiology, vol. 78, no. 4, pp. 1425-1431, 1995. 


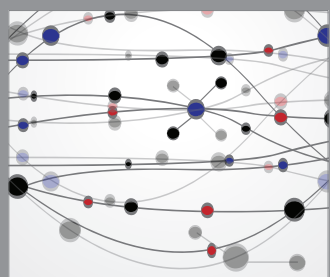

The Scientific World Journal
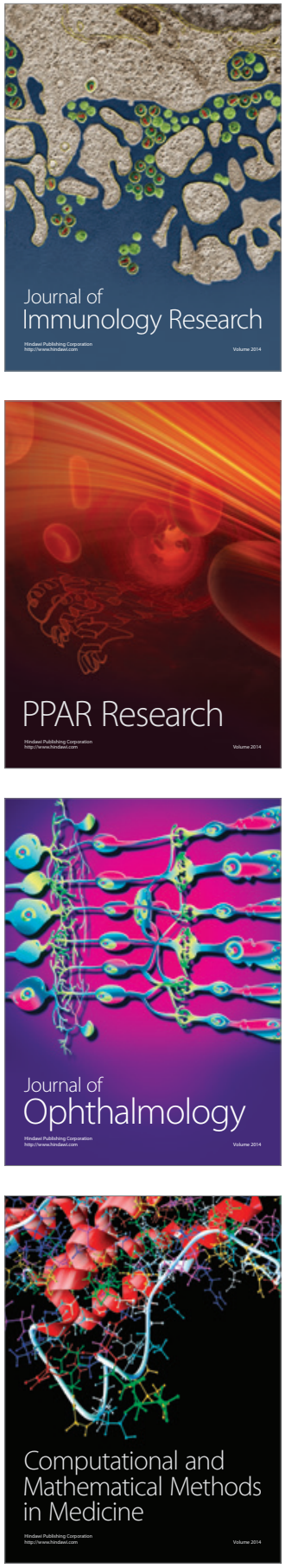

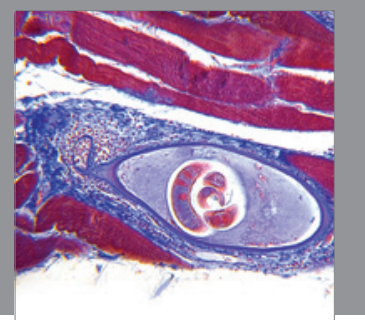

Gastroenterology

Research and Practice
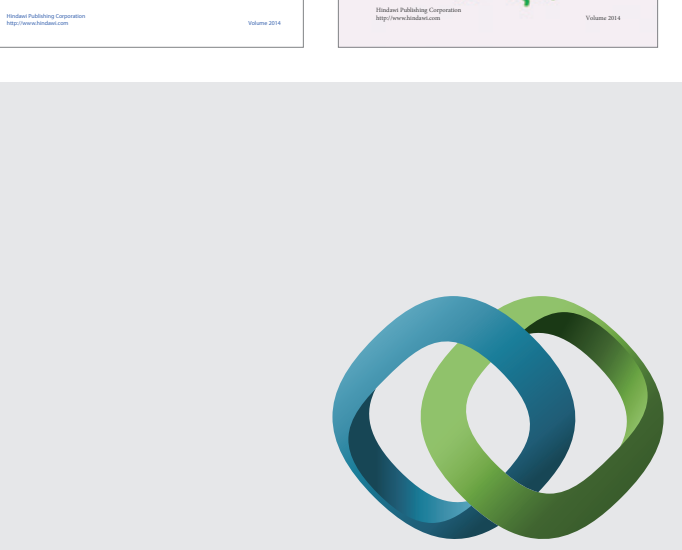

\section{Hindawi}

Submit your manuscripts at

http://www.hindawi.com
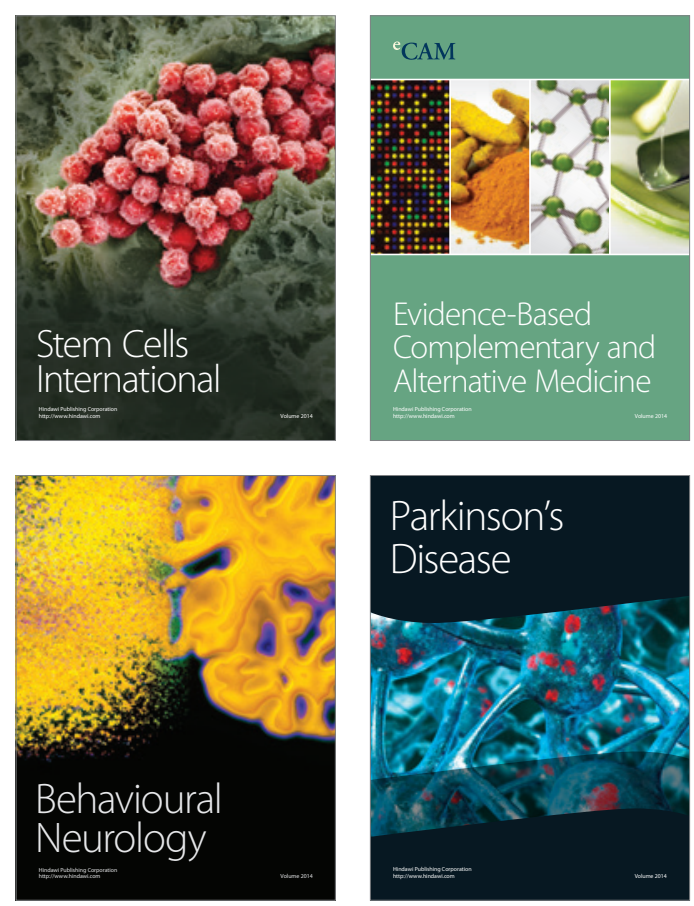

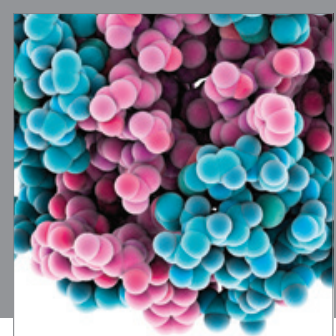

Journal of
Diabetes Research

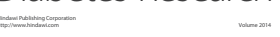

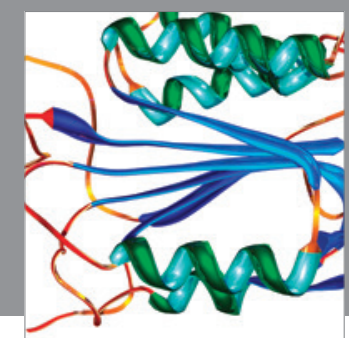

Disease Markers
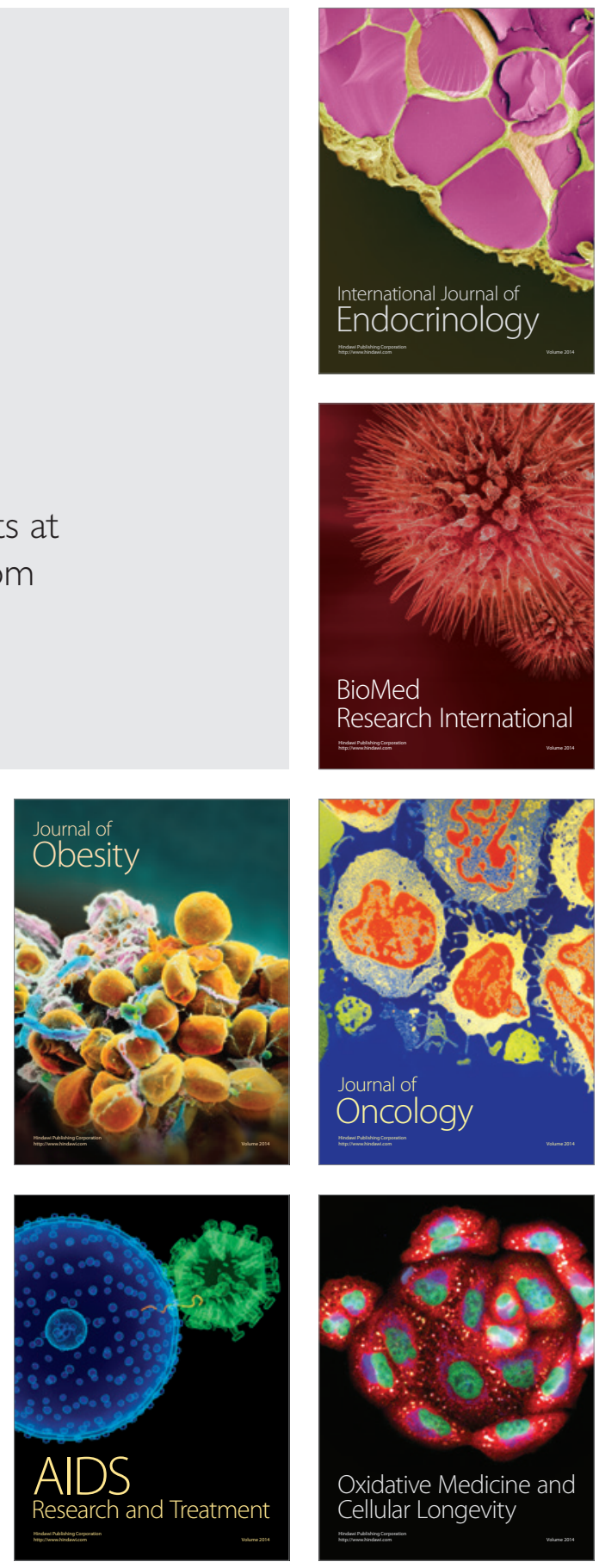